\section{Sample preparation for laser-microdissection of soybean shoot apical meristem}

\author{
Chui E. Wong, Mohan B. Singh, \\ Prem L. Bhalla \\ Plant Molecular Biology and \\ Biotechnology Group, ARC Centre \\ of Excellence for Integrative Legume \\ Research, Melbourne School of Land \\ and Environment, The University \\ of Melbourne, Parkville, Victoria,
} Australia

\section{Abstract}

The shoot apical meristem houses stem cells responsible for the continuous formation of aerial plant organs including leaves and stems throughout the life of plants. Laser-microdissection in combination with high-throughput technology such as next generation sequencing permits an in-depth analysis of molecular events associated with specific cell type of interest. Sample preparation is the most critical step in ensuring good quality RNA to be extracted from samples following laser-microdissection. Here, we optimized the sample preparation for a major legume crop, soybean. We used Farmer's solution as a fixative and paraffin as the embedding medium for soybean shoot apical meristem tissue without the use of any specialized equipment. Shorter time for tissue fixation (two days) was found to be critical for the preservation of RNA in soybean shoot apical meristem. We further demonstrated the utility of this method for different tissues derived from soybean and rice. The method outlined here shall facilitate studies on crop plants involving lasermicrodissection.

\section{Introduction}

The laser microdissection technique was first described in 1996 and since then it has been used in studies that aimed at isolating specific cell types from a heterogenous tissue sample. ${ }^{1}$ The technique has thus enabled the analysis of transcript profiles associated with the specific cell type of interest.

Sample preparation is the most critical step in ensuring the quality of RNA from lasermicrodissected plant samples suitable for downstream application. The main challenge in the technique is to find an appropriate fixation method that preserves the resolution of tissue samples and yet with relatively intact RNA that allows for downstream application.
RNA extraction methods from plant tissues following laser micro-dissection is of interest. ${ }^{2-5}$ Kerk et al. ${ }^{3}$ reported that tissue fixation in Farmer's solution composed of 75\% ethanol, $25 \%$ acetic acid provides good quality RNA from samples obtained by laser-microdissected and paraffin-embedded sections although their preparation involves conditions such as long duration of paraffin infiltration at high temperature that are detrimental to RNA. While some protocols call for the use of specialized equipment in speeding up the sample preparation step and hence minimizing RNA degradation, ${ }^{4,5}$ others do not give sufficient details for the protocol to be carried out successfully. Furthermore, a sample preparation method for important legume crops such as soybean, a global crop for oil and protein and increasingly priced for its use in biofuel production, is yet to be reported.

\section{Case Report}

We are interested in obtaining the transcript profile of the stem cell population in the shoot apical meristem of soybean. We initially followed a protocol for the fixation of tissues adapted from Jackson $1991^{6}$ and Kerk et al., ${ }^{3}$ that calls for more than 48 hours of wax infiltration of samples at $58-60^{\circ} \mathrm{C}$ following dehydration of tissue samples. Following tissue fix-
Correspondence: Prem Bhalla, ARC Centre of Excellence for Integrative Legume Research, The University of Melbourne, Parkville, VIC 3010, Australia. Tel./ Fax: +61.3.8344.9651.

E-mail: premlb@unimelb.edu.au

Key words: laser-microdissection, shoot apical meristem, soybean.

Acknowledgements: we gratefully acknowledge financial support from the Australian Research Council in the form of the ARC Centre of Excellence grant (CE0348212) for this project.

Contributions: CEW designed and carried out the experiment and wrote the manuscript. PLB and MBS were responsible for the overall design of the project and experiments, manuscript revision and editing.

Conflict of interests: the authors report no conflict of interests.

Received for publication: 19 0ctober 2011. Revision received: 12 March 2012.

Accepted for publication: 6 April 2012.

This work is licensed under a Creative Commons Attribution NonCommercial 3.0 License (CC BYNC 3.0).

(C) Copyright C.E. Wong et al., 2012

Licensee PAGEPress srl, Italy

International Journal of Plant Biology 2012; 3:e3 doi:10.4081/pb.2012.e3

\section{Gene-specific primer synthesized cDNA}

a

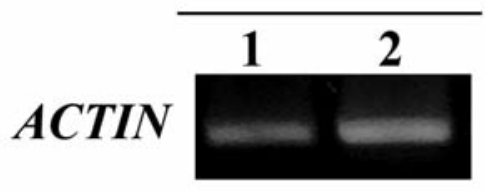

b

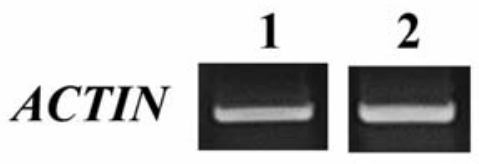

c

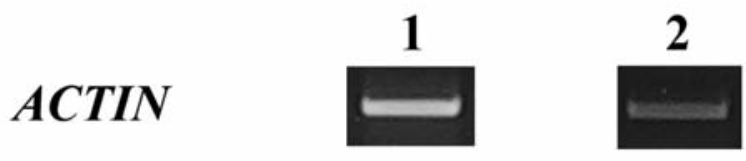

\section{OligodT Synthesized cDNA}
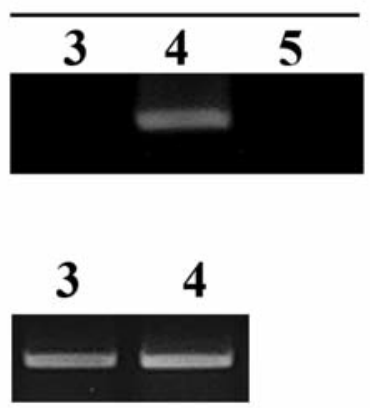

Figure 1. Reverse transcriptase-polymerase chain reaction analysis of RNA extracted from soybean. A) 1,3: RNA extracted from one $10 \mu \mathrm{m}$ section fixed with $48 \mathrm{hrs}$ of wax infiltration; 2,4: Positive control using RNA extracted from fresh tissues; 5: negative control without reverse transcriptase. B) 1,3: RNA extracted from one soybean dissected shoot apex prior to wax infiltration; 2,4: Positive control using RNA extracted from fresh tissues. C) RNA extracted from one $10 \mu \mathrm{m}$-section fixed with the modified protocol. 


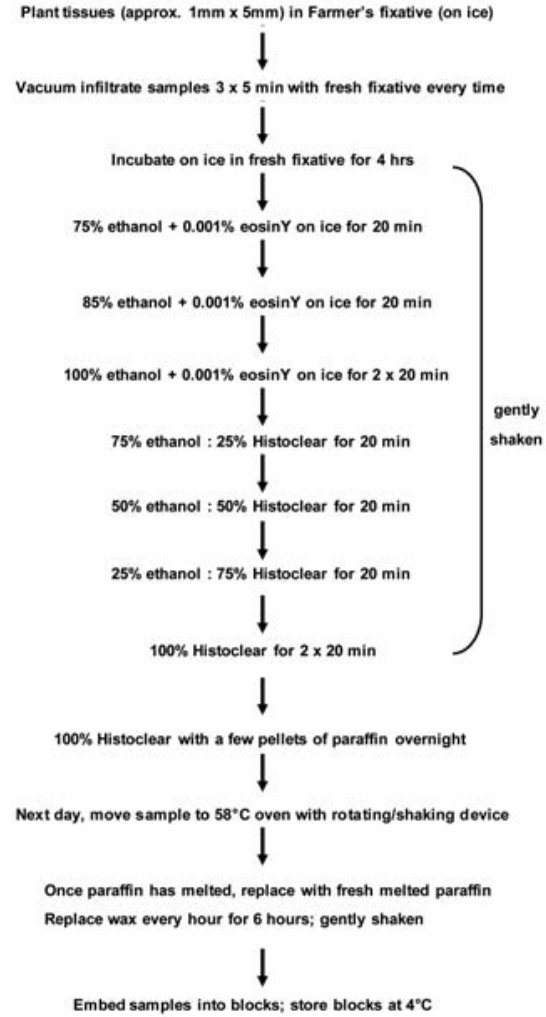

Figure 2. A flow chart representing the optimized sample fixation (modified from Jackson and Kerk et al.). ${ }^{6}$

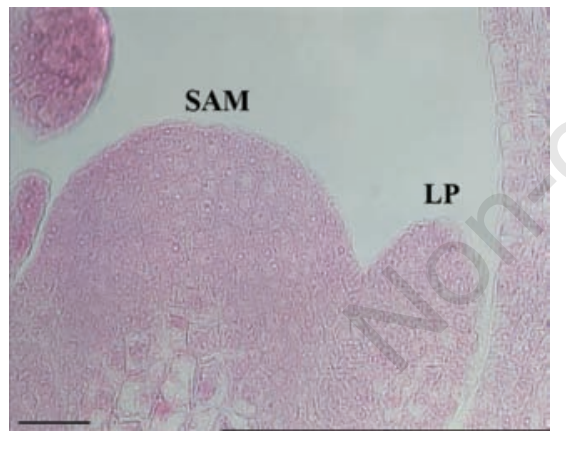

Figure 3. A transverse section of soybean shoot apex. Dissected soybean shoot apexes were prepared with the modified fixation protocol as outlined in Figure 2. Paraffin blocks were then sectioned into 10 $\mu \mathrm{m}$ thickness before being stretched on pre-warmed DEPC $\mathrm{H} 2 \mathrm{O}$ bath $\left(37^{\circ} \mathrm{C}\right)$ and placed on PALM membrane slides $(1 \mathrm{~mm}$ PEN). Slides were then dried for $3 \mathrm{hrs}$ at $37^{\circ} \mathrm{C}$ and stored at $4^{\circ} \mathrm{C}$ until LM. Immediately before LM, slides were deparaffinized in Histoclear for $5 \mathrm{~min}$ and air-dried. Section appeared pink due to eosin Y staining. SAM: shoot apical meristem; LP: leaf primordia. Scale bar represents $20 \mu \mathrm{m}$.

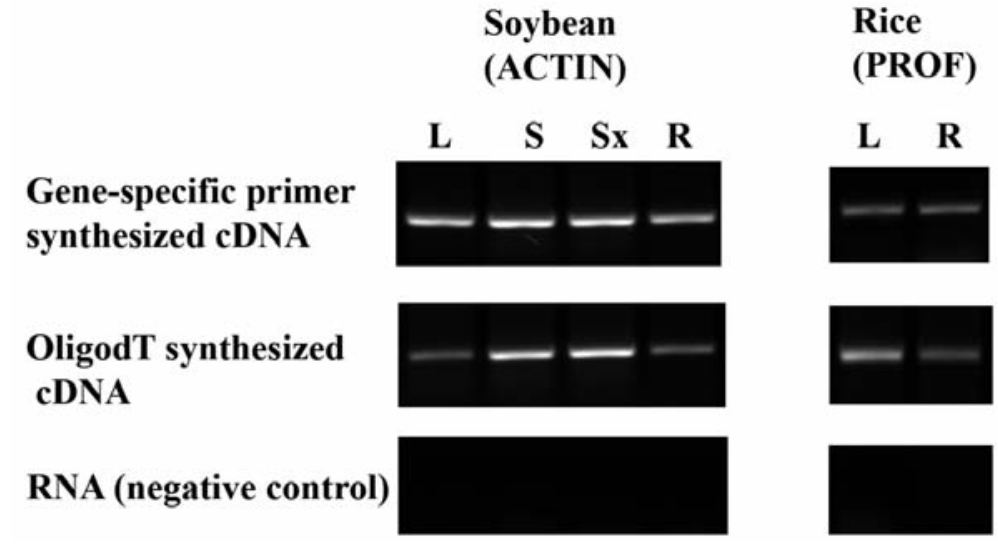

Figure 4. Reverse transcriptase-polymerase chain reaction (RT-PCR) analysis of RNA extracted from soybean or rice tissues. RNA extracted from different tissues subjected to the fixation step outlined in Figure 2 was used as template for RT-PCR analysis. L, leaf; S, stem, Sx, shoot apex, R, root. PROF corresponds to rice PROFILIN-2 (Os06g05880).

ation, the quality of RNA was accessed via Reverse transcriptase-polymerase chain reaction (RT-PCR) of a housekeeping gene, ACTIN, using Promega Access One Step RT-PCR system with ACTIN primer for the cDNA synthesis. For RNA extraction, one whole tissue section $(10 \mu \mathrm{m})$ was scraped into RNase-free microfuge tubes using a scalpel and RNA was then extracted following Arcturus PicoPure RNA kit with an on-column DNAse digestion step incorporated according to manufacturer's instruction. Though the PCR product of the expected size was observed indicating reasonable good quality RNA, we could not obtain amplified RNA from laser-microdissected samples of the same batch of tissue sample using Ambion MessageAmp ${ }^{\mathrm{TM}}$ II aRNA Amplification kit (data not shown).

\section{Discussion}

The only difference between the method used in the quality assessment and RNA amplification experiment is the use of a gene-specific primer in the former and an oligodT with adaptor in the latter. We thus suspected degradation of RNA with majority if not all losing their polyA tail. We next tested this hypothesis by carrying out cDNA synthesis using genespecific primer or oligodT. As expected, no PCR product could be amplified from oligodTprimed cDNA (Figure 1A). To identify the step where degradation of RNA takes place, we extracted RNA from one shoot apex after infiltration with Histoclear prior to wax infiltration step. As shown in Figure 1B, the quality of RNA was relatively intact as indicated by the presence of PCR product from template derived from either oligo-dT or gene-specific primed cDNA synthesis. We thus concluded that the RNA degradation must have occurred during the prolonged wax infiltration at $58^{\circ} \mathrm{C}$. When we shortened the wax infiltration step to $6 \mathrm{hrs}$ (Figure 2), we successfully obtained PCR products from both oligo-dT primed and gene-specific primed cDNA although the intensity of the band for the oligo-dT primed cDNA was less than the gene-specific primed cDNA synthesis (Figure 1C). We nevertheless proceeded to prepare samples for laser-microdissected and amplified RNA from RNA extracted from the laser-microdissected tissues using Ambion MessageAmpTM II aRNA Amplification kit. We successfully obtained close to $80 \mu \mathrm{g}$ of amplified RNA from two rounds of amplications starting from approximately 200 cells. When tissue sections were checked for histological quality, this shortened wax infiltration step was sufficient to give sections with clear resolution (Figure 3).

We subsequently investigated the suitability of this optimized procedure for tissues other than SAM as well as for other crops such as rice. To this end, tissues from soybean (leaf, stem and primary root) and rice (leaf and root) were cut into $1 \mathrm{~mm} \times 5 \mathrm{~mm}$ using a razor blade. These were subjected to the fixation step as outlined in Figure 2 and RNA was extracted from these tissues prior to the embedding step. The quality of RNA was assessed using the same procedure as above. As shown in Figure 4, the optimized fixation 
method resulted in RNA of a reasonable quality for all soybean and rice tissues as PCR products could be obtained from both oligo-dT primed and gene-specific primed cDNA.

\section{Conclusions}

In summary, we have described an optimized sample fixation method for obtaining RNA of a reasonable quality from lasermicrodissected cells. Our study has further highlighted that RNA quality assessment via RT-PCR using gene-specific primed cDNA synthesis step is not a reliable indicator.

\section{References}

1. Emmert-Buck MR, Bonner RF, Smith PD, et al. Laser capture microdissection. Science 1996;274:998-1001.

2. Nakazono M, Qiu F, Borsuk LA, Schnable PS. Laser-capture microdissection, a tool for the global analysis of gene expression in specific plant cell types: identification of genes expressed differentially in epidermal cells or vascular tissues of maize. Plant Cell 2003;15: 583-96.

3. Kerk NM, Ceserani T, Tausta SL, et al. Laser capture microdissection of cells from plant tissues. Plant Physiol 2003;132: 27-35.
4. Takahashi H, Kamakura H, Sato Y, et al. A method for obtaining high quality RNA from paraffin sections of plant tissues by laser microdissection. J Plant Res 2010; 123:807-13.

5. Inada N, Wildermuth MC. Novel tissue preparation method and cell-specific marker for laser microdissection of Arabidopsis mature leaf. Planta 2005;221: 9-16.

6. Jackson D. In situ hybridization in plants, In: Gurr SJ, McPherson MJ, Bowles DJ. Molecular plant pathology: a practical approach. Oxford: Oxford University Press; 1991. pp 163-174. 